\title{
CINCO DESENTERRADOS Y UN SOBREVIVIENTE 0 LOS EMBAJADORES DE LA PROFUNDIDAD
}

\section{Alain Sicard}

Catedrático de Literatura Latinoamericana en la Universidad de Poitiers y Director del Centro de Investigaciones Latinoamericanas de la misma universidad, es autor de varios libros entre los que destaca El pensamiento poético de Pablo Neruda (1981), y Residence sur la terre de Pablo Neruda (2000), poeta del que ha sido traductor. Es director de los Coloquios Internacionales de Poitiers en los que se ha estudiado sistemáticamente una parte importante de los autores latinoamericanos de hoy. Es autor de numerosos artículos sobre autores contemporáneos.

\author{
ALAIN SICARD
}

1

Lo primero que se impone, a la lectura del poema de la segunda Residencia, es esta vehemencia casi frenética, conjugada en primera persona. Nada de ángeles ni de trompetas : solamente el Verbo, movilizado, protagonizado para una resurrección:

Quiero una oreja, un ojo, un corazón herido dando tumbos, un hueco de puñal hace tiempo hundido en un cuerpo hace tiempo exterminado y solo, quiero unas manos, una ciencia de uñas, una boca de espanto y amapolas muriendo, quiero ver levantarse del polvo inútil un ronco árbol de venas sacudidas, yo quiero de la tierra más amarga, entre azufre y turquesa y olas rojas y torbellinos de carbón callado, quiero una carne despertar sus huesos aullando llamas...

\section{2}

Ese anhelo jadeante, como a ciegas... ¿Será porque estas líneas que escribo están destinadas a Alicante? Empujo la reja de hierro del cementerio. Estoy en Orihuela. En aquel mes de enero del 36, un grupo de gente está reunido y escucha la voz de un joven -casi un muchacho- que se eleva parece que desde la misma tumba:
Yo quiero ser llorando el hortelano de la tierra que ocupas y estercolas, compañero del alma, tan temprano.

Quiero escarbar la tierra con los dientes, quiero apartar la tierra parte a parte a dentelladas secas y calientes.

Quiero minar la tierra hasta encontrarte

y besar tu noble calavera

y desamordazarte y regresarte.

Miguel Hernández llora a su amigo Ramón Sijé «con quien tanto quería». O con quien había querido tanto. Una sombra ronda allí en torno: la del nuevo amigo, Pablo Neruda. En la desesperación del poeta orador, tal vez un asomo de mala conciencia, como si la nueva amistad fuera una traición y ésta fuera el precio con que había que pagar para enterrar a la Tradición, nacer a la Poesía.

\section{3}

\section{Madrid en marzo.}

Todo molido entre las confusiones, todo si esperanzas decaído, todo en la sima seca alimentado entre los dientes de la tierra dura.

Aquello que vi en la Puerta del Sol. Atardecía. No era, no, un cementerio, no había poemas ni discursos. Al pié del muro, la ola silenciosa y petrificada del recuerdo: alum-
Cinco desenterrados y un sobreviviente o los embajadores de la profundidad 


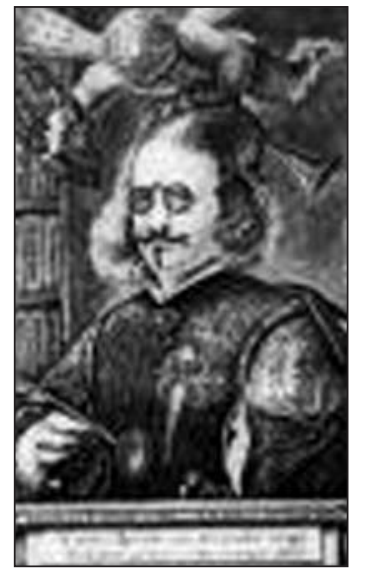

Francisco de Quevedo.

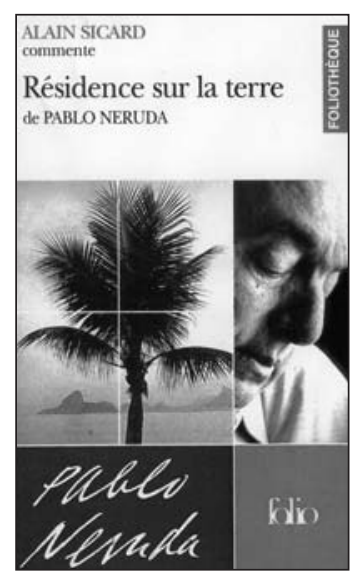

in

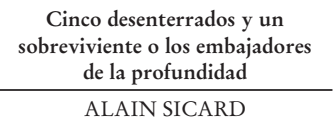

Cinco desenterrados y un de la profundidad

ALAIN SICARD brados por las velas, papeles, objetos de $s u$ pertenencia. Recordé un poema del año setenta: «Ven acá sombrero caído, / zapato quemado, juguete, / o montón póstumo de anteojos, / o bien, hombre, mujer, ciudad, / levántense de la ceniza / hasta esta página cansada, / destituida por el llanto». Fin de mundo. Se llama «Fin de mundo» el libro de Neruda de donde hasta mí llegaron entonces estos versos aquella tarde, en Madrid. La misma sangre en las mismas calles.

En uno de los papeles, una mano había escrito: «...aquellos doscientos muertos que murieron...». «Viban los compañeros!» escribía en el aire, con su dedo grande, Pedro Rojas. Murierón: basta con un acento desplazado por la emoción, para que doscientos muertos sea uno solo, para que el cadáver se levante, se eche a andar...

\section{4}

Condes. El otro -quiero decir el de Orgaz, cuyo entierro inmortalizó El Greco- no necesita, por famoso, ningún tipo de resurrección. El cuadro que el toledano pinta en 1586 a pedido del cura de Santo Tomé celebra el reconocimiento oficial de un milagro ocurrido cuando el entierro del conde en 1323. Orgaz versus Villamediana. Cristiano ejemplar el primero, gozando del favor de Dios y del respeto de sus conciudadanos. Tahur y pendenciero - poeta por añadidura- el segundo, enamorado de la Reina. Cuesta creer que provocó un incendio para tenerla entre sus brazos. No murió, como el primero entre suntuosas telas y brocados, rodeado de aquellos adustos señores toledanos en los que se esmeró el pincel del Greco, si no solo, en la calle, asesinado.

\section{5}

El Greco pinta el misterio del paso del alma a la vida eterna. El espacio pictórico está dividido en dos : Tierra / Cielo, Cuerpo / Alma. En la parte superior las formas se desvanecen, se disuelven. La disolución es, en el cuadro del artista toledano el punto de llegada. En el poema de Neruda, ella es el punto de partida. El más allá es un más acá, sin ninguna solución de continuidad con un aquí despojado de toda trascendencia. El conde regresa vestido de las insignias materiales de la profundidad. «Cuelgan de sus rodillas y sus hombros / adherencias de olvido, hebras del suelo, / zonas de vidrio roto y aluminio, / cáscaras de cadáveres amargos....».

\section{6}

Viajes a la profundidad: Quevedo. «En el fondo del pozo de la historia, como un agua más sonora y brillante, brillan los ojos de los poetas muertos». Así empieza «El viaje al corazón de Quevedo» (1942), y así continúa nuestro viaje. Quevedo: ¿otro desenterrado? $¿ \mathrm{O}$ el mismo? La intertextualidad desentierra cuerpos cuya identidad es no tenerla.

\section{7}

Para empezar: ¿cuál Quevedo? Uno piensa en «El sueño del juicio final». Pero el Juicio, determinante en la perspectiva totalmente cristiana y trascendente $-\mathrm{a}$ pesar de su alcance satírico- de Quevedo, está ausente del poema de Neruda. El Conde no sale del sepulcro para oír una verdad supra-terrestre. Él es el depositario de una verdad -de un «secreto»- que encontró debajo de la tierra. Y que blande como un mensaje. Como un poema.

8

Si Neruda reconocía en Quevedo su «padre mayor y visitador de España», su inclinación íntima no iba hacia el autor satírico de los «Sueños» sino hacia el poeta de los sonetos a la muerte. Estos -y no el «Sueño del Juicio final»- son, más allá de las coincidencias y de las desviaciones temáticas, el verdadero intertexto de homenaje residenciario.

9

Los sonetos sobre la muerte, o la lectura materialista que Neruda hace de ellos en el «Viaje al corazón de Quevedo». En 1942, Neruda no usa este epíteto. Habla, a propósito de Quevedo, de una «metafísica inmensamente física». Pero añade: «lo más material de su enseñanza».

10

La lección que Neruda recibe de Quevedo es la inversa del Eclesiastés. En la muerte, el poeta descifra no la vanidad de las vidas te- 
rrestres sino su «rumorosa materia», su inagotable riqueza: «Así tienen en él su explicación la abeja, la constucción del topo, los recónditos misterios florales». Esta frase echa una luz sobre la preponderancia, en la intertextualidad nerudiana, de Quevedo sobre Góngora. El poeta del «Canto general» o de las «Odas elementales» podrá dejarse seducir por la estructura complicada del caracol o el milagro transparente de la cebolla, su pasión por lo real se sitúa más allá. La «explicación». El poeta como «explorador del ser». Cada objeto, cada flor es un enigma. Pablo Neruda, Francisco de Quevedo: «caballero(s) del conocimiento».

\section{1}

«La agricultura de la muerte», estas palabras de Don Francisco que tanto le gustaba al Don Pablo de Isla Negra. La misteriosa continuidad de las vidas y de las muertes ¿no será el secreto que el Conde nos entrega desde lo más hondo de la tierra?

\section{2}

Una línea del «Viaje al corazón de Quevedo»: «Este es un viaje al fondo escondido que mañana se levantará viviente. Es un viaje al polvo. Al polvo enamorado que mañana volverá a vivir». Y un recuerdo.

Una cena-¿en qué año? ¿64? ¿65?- en mi casa en el campo, cerca de Poitiers. Éramos los tres: Pablo, Amédée Mas, especialista de la obra de Quevedo (que, por amistad había aceptado dirigir un trabajo bastante alejado de sus preocupaciones), y yo. Entre dos recetas de cocina y más de dos tragos de vino de borgoña, una discusión se había abierto sobre el último verso del famoso soneto de Quevedo: «polvo serán, mas polvo enamorado». Pablo defendía su tesis, hablaba de la «agricultura de la muerte», del polvo que no es polvo, de la vida que renace de cada muerte, del amor vencedor de la ceniza. Mi buen Maestro Amédée, lo escuchaba, socarrón al par de admirativo, y porfiaba, sonriente, «un simple cliché de la littérature précieuse!»: un tópico barroco no más.

\section{3}

En su lecho de muerte, cuando utiliza sus últimas fuerzas para tirar contra los enemigos de la Revolución Chilena su «piedra araucana», el chileno emprende su último viaje al «sabio subterráneo», al "padre profundo»: «Viviendo entre el océano y Quevedo, / es decir entre graves desmesuras...».

\section{4}

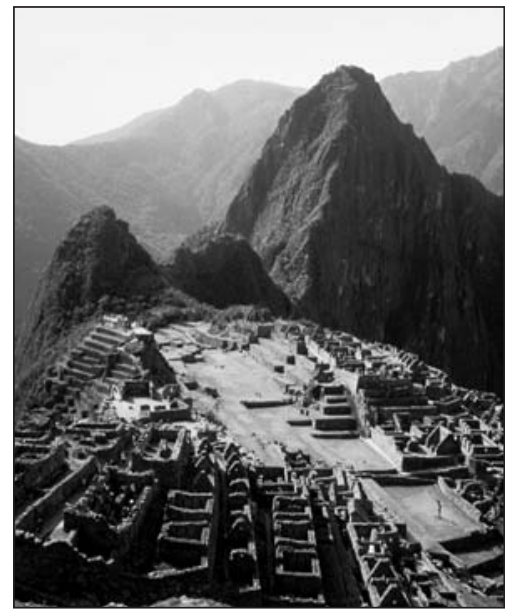

Machu Picchu.

Tan interminable como el viaje a la semilla de Quevedo es el viaje a la propia semilla, a la infancia.

Entrada furtiva a otro cementerio, lejos de Orihuela, en Temuco. El año es 32. El desenterrado se llama José

del Carmen Reyes Morales a quien trasladan de su nicho para que descanse junto a su esposa que acaba de fallecer. En el grupo silencioso que rodea la tumba está su hijo, el mismo que hace doce años, en una casa de madera cerca de aquí, decidió cambiar de apellido para «tener todos los nombres a la vez». Pero ninguno de los presentes lo llaman aún Pablo Neruda. La escena está narrada en un breve texto, probablemente escrito en 1938, titulado «La copa de sangre», y que su autor no integró a ninguno de sus libros: «demasiado personal» contestó el poeta a la pregunta que le hizo un día Hernán Loyola al respecto.

15

"Cuando remotamente regreso y en el extraordinario azar de los trenes, como los antepasados sobre las cabalgaduras, me quedo sobredormido y enredado en mis exclusivas propiedades...». Una larga frase de veintiún líneas y de manifiesto cuño proustiano lleva al protagonista de «La copa de sangre» hacia la provincia de la infancia. Viaje a la semilla, viaje al inconsciente. Hacia el fondo. Búsqueda: «...como si aquella tierra boscosa y perpetuamente en lluvia tuviera un secreto mío que no conozco, que no conozco y que debo saber, y que busco perdidamente, ciegamente...».

\section{6}

Desenterrar el secreto.

17

Buscar en el padre muerto el secreto enterrado en el hijo. Ser su propio desenterrado. 


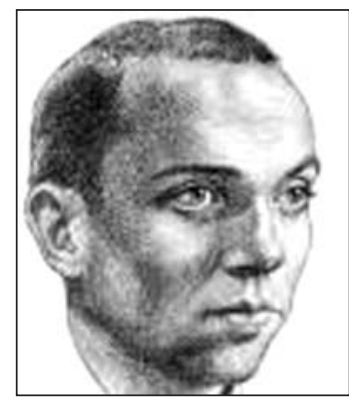

Miguel Hernández. Dibujo de Antonio Buero Vallejo en 1939
La copa de sangre fascina por la juxtaposición de dos recuerdos aparentemente inconexos: la copa de sangre que el niño bebe «pálido, indeciso, perdido en la desierta infancia», y el desentierro del padre en el cementerio de Temuco, años después. Entre ambos episodios, ¿qué vínculo misterioso une la sangre recogida en la copa -acaban de matar a un cordero- y el agua acumulada por las lluvias dentro del ataúd. ¿Qué secreto?

«Ahora bien, esta agua terrible, esta agua salida de un imposible insondable, extraordinario escondite, para mostrarme a mí su torrencial secreto, esta agua original y temible me advertía otra vez con su misterioso derrame mi conexión interminable con una determinada vida, región y muerte». El secreto se entrega al niño ya hecho padre, hecho aquel «centauro» que en sus tíos envidiaba. La revelación ha sido pagada por la sangre. ¿ Redimir al cordero?

\section{0}

Macchu Picchu. Una ascensión que es un hundimiento hacia la profunda zona del dolor diseminado, hacia el esclavo desenterrado por la palabra. Un viaje hacia el corazón de la historia. Hacia su secreto.

\section{1}

La muerte grande se burla de los anacronismos. Todos los esclavos un esclavo. Todos los desenterrados aquel «recién sin arañas», aquel «conde dulce, en la niebla».

\section{2}

Desentierro textual. "Oh recién despertado de las minas!». Hernán Loyola lee, en este verso de «El desenterrado», una de las manifestaciones secretas del texto: «la de establecer una conexión de sentido entre poesía asesinada (Conde de Villamediana) y mineros asesinados, refiriéndose a los muertos durante la represión militar en Asturias (octubre-noviembre de 1934)».
El esclavo de las minas asturianas. Asesinado. Como el Conde, asesinado.

\section{4}

«Sube a nacer conmigo, hermano». ¿Cuál es el desenterrador? ¿cuál el desenterrado? El desentierro como metáfora de un nacimiento. A la propia geografía, a la propia historia, al propio ser. Al poema.

\section{5}

Regreso al Desenterrado de la segunda $R e-$ sidencia.

Todo molido entre las confusiones, todo sin esperanzas decaído...

Uno de los núcleos principales del libro es aquel lugar del texto donde se acumula lo que llamaría la totalidad negativa. Las muertes, las destrucciones se acumulan en un «todo» que las suma y les hace como una corona fúnebre. Ejemplos: «La calle destruida», o, en la Tercera Residencia, "Canto sobre unas ruinas». Este es el punto ciego de las Residencias, de donde sacan su energía sombría. Allí se nutre el dinamismo paradojal del desenterrado:

\section{6}

Dialéctica de la enumeración. Ella es la figura de la dispersión -«caótica» la llamó el gran Amado Alonso-, pero también es lo que la estructura y la salva del caos. "Alberto Rojas Jiménez viene volando», que dice la desintegración de la muerte es uno de los poemas más estructurados de Residencia en la tierra. La enumeración, en «El desenterrado» se invierte para entonar, desde el «todo» informe de la muerte, el himno de la forma y de la recomposición.

27

La vehemencia de aquel ahínco de recomposición. Sobre todo: la implicación personal del poeta, agravada por la sintaxis, el anhelo de apropiación de un cuerpo como si fuera el propio: «Quiero una oreja, un ojo...».
Cinco desenterrados y un de la profundidad ALAIN SICARD 
¿Qué es lo que viene emergiendo de lo informe? ¿Qué es lo que está naciendo de este terrible juego de tensiones sino el poema? Y ¿quién es este recién nacido de sus propias palabras sino el sujeto poético, protagonista del poema que lo engendra?

\section{9}

El sujeto poético de la profundidad, desnudo, despojado de toda identidad, o sin otra identidad que ésta que le confiere «la entrada a la profundidad de las cosas en un acto de arrebatado amor». Toda la poesía de Neruda repetirá este gesto, nacerá de aquel secreto desenterrado e impenetrable.

\section{0}

«Yo soy el sumergido de aquellas latitudes» (Cantos ceremoniales: «Cataclismo»)

\section{1}

«Embajadores de la profundidad»: otro título posible para esta galería de desenterrados. En francés no funciona. "Ambassadeurs du profond». Falta el sema «bajar» contenido en «embajador».

32

«Entrada a la madera», su secreto entroncamiento con «El desenterrado» que invierte la verticalidad, dialectiza el caer.

33

Entierro / desentierro, dos caras de la misma medalla. El pozo, su imagen complicada en los últimos versos de «Eternidad» (Canto general VII «Canto general de Chile», OC, p.638): «Pero yo soy el nimbo metálico, la argolla / encadenada a espacio, a nubes, a terrenos / que toca despeñadas y enmudecidas aguas, / y vuelve a desafiar la intemperie infinita».

\section{4}

Enterrarse, viajar a lo inhabitado, y regresar levantando en la mano «el secreto de la espuma».
La espuma: discreta referencia al océano, figura máxima de lo inhabitado. Abundan las versiones aquáticas del «sumergido». Emblemática es, en el Tercer libro de las odas, la «Oda al buzo». El buzo brota del mar como el desenterrado de la tierra. Es un ser anfibio, «medio mar / y medio tierra». Tuvo que aprender allí abajo -en «aquellos cementerios mojados» dice el texto- a «tener / apenas / pensamientos de agua». Habitar lo inhabitado, y regresar «tambaleante / entre la oscuridad de dos abismos».

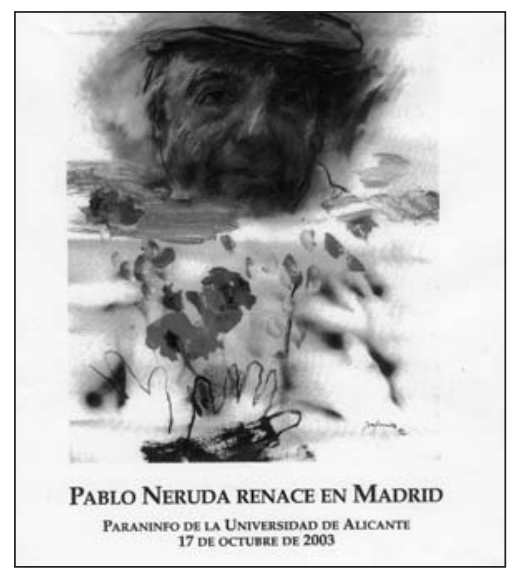

35

El seudónimo, la identidad de quien la ha perdido dentro de la profundidad. Los desenterrados serán su máscara. $\mathrm{O}$, al revés: Pablo Neruda será un torpe disfraz para viajar a su país profundo: para morir y resucitar en cada poema.

36

«Cuelgan de sus rodillas y sus hombros / adherencias de olvido, hebras del suelo, / zonas de vidrio roto y aluminio, /cáscaras de cadáveres amargos, / bolsillos de agua converti$\mathrm{da}$ en hierro, / y reuniones de terribles bocas / derramadas y azules, / y ramas de coral acongojado / hacen corona a su cabeza verde, / y tristes vegetales fallecidos / y maderas nocturas lo rodean».

En el año 47 el poeta escocés George S. Frazer visita al poeta en Santiago. Lo observa y piensa «en un dios del mar, arrojado sobre la orilla, con algas y restos de naufragios que todavía le cuelgan...». Aragon: "Il a l'air d'un poisson pour l'oeil et le silence»: («un pez por el ojo y el silencio»). Celaya: «un poeta informe como suelen serlo las criaturas nacidas entre el agua y el sueño». ¿Es posible que un poeta llegue a parecerse a su poesía? ¿que la encarne en su cuerpo, en sus modales? En su voz. Sólo puedo leer la poesía de Neruda renunciando a mi propia voz, oyendo la gangosa voz de Pablo leyendo dentro de mi silencio. La cuestión no es si lee bien o mal. La cuestión es la poesía encarnada en una voz, como Frazer, Celaya o Aragon la vieron encarnada en su cuerpo.

\footnotetext{
Cinco desenterrados y un sobreviviente o los embajadores de la profundidad ALAIN SICARD
} 


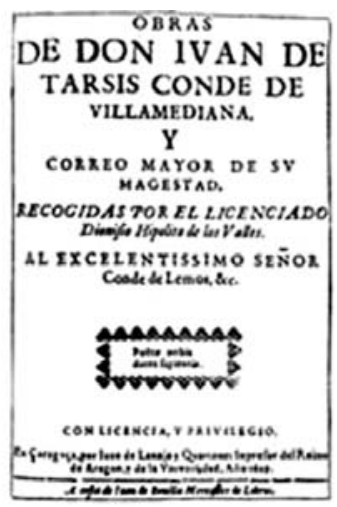

Zaneas. 109

Obras de Villamediana.
El homenaje al Conde de Villamediana: retrato del poeta como desenterrado. ¿O autoretrato?

Abro la «Geografía infructuosa». El último poema. Se titula «El sobreviviente saluda a los pájaros». El convaleciente, en La Manquel, su casita de Normandía, da sus primeros pasos al aire libre. "Salí vestido de agua, me extendí como un río / hacia el horizonte que los más antiguos geógrafos / tomaron como final del presupuesto terrestre: / yo fui entre las raíces, bañando con palabras / las piedras, resonando, como un metal del mar».

Es preciso fundar otra vez la morada, la residencia en la tierra. Debajo de la tierra. Y otra vez desenterrarse. Renacer.

\section{8}

Retrato del poeta como desenterrado y como sobreviviente. Morir es el gesto poético por excelencia. Una muerte a la que uno sobrevive, siempre que lo habite ese afán apasionado, siempre que no le abandone la palabra: «Yo quiero de la tierra más amarga, / entre azufre y turquesa y olas rojas / y torbellinos de carbón callado, / quiero una carne despertar sus huesos aullando llamas».
¿Qué tierra para el desenterrado? ¿Qué residencia en la tierra? En los últimos versos del poema, el sobreviviente pide disculpa al lector por su consubstancial derelicción. Le ruega que respete su «remota soberanía». Entonces la imagen del Conde asesinado y la del chileno redivivo se confunden en la misma silueta del desenterrado, del torpe recién salido de la tierra : «...déjame / titubeante, inseguro, salir de las regiones / perdidas, de la tierra que me enseñó a llover, / déjame sacudir el carbón, las arañas, / el silencio: y verás que soy tu hermano».

40

Coda o epílogo: otro cementerio. El último. En Santiago, un 25 de septiembre. No un grupo de pesonas sino todo un pueblo rodea el sepulcro. Una voz, mil voces como levantándose de la tumba: «Camarada Pablo Neruda: Presente!».

«Abrazó al primer hombre; echose a andar...». 